\title{
Economic assessment and optimizing of the solar water heating system
}

\author{
Jan Skovajsa ${ }^{1, *}$ and Martin Zálešák ${ }^{1}$ \\ ${ }^{1}$ Tomas Bata University in Zlin, Faculty of Applied Informatics, Department of Automation and Control Engineering, Nad Stranemi \\ 4511, Zlin, Czech Republic
}

\begin{abstract}
The article deals with the economic evaluation of investment and optimization of the solar water heating system for family houses. From the point of view of solar systems, the optimal solution is based on the specific application of it. The design is dependent on the location of solar thermal collectors and ration between active aperture area and real daytime consumption. Common calculations according to actual standards often give overstated results, which also reflected in the value of the investments. The article presents the research of optimal parameters of the thermal solar system for preparing of domestic hot water. A combination of related standards and software TRNSYS are used to find optimal parameters. Thanks to created and verified simulation models, it is possible to design parameters so as to avoid underdimensioning or over-dimensioning of the solar system. Energy price is another factor affects the payback period of investments. This is affected by the used energy sources and their combination. For example, buildings that use electricity to heat water or heating have different energy charges than a building that uses natural gas. So, the aim is to find technically and economically efficient solution.
\end{abstract}

\section{Introduction}

The article focuses on calculations of the solar water heating system based on the relevant standards, and its dynamic simulations. The solar water heating system is very popular and its applications are still growing up [x5]. One of the relevant standards is CSN 060320 (based on EN 12828+A1 and EN 12831-3) which is used for designing of the heating systems in buildings. $[2,3,4]$ However, this does not include solar water systems design. For this purpose, EN 15316-3 and TNI 730302 can be used. [5,6] The following chapters describe the procedure for calculation of these standards and methods in a simplified way.

\subsection{Generation of domestic hot water}

Daily energy requirement for domestic hot water (DHW) preparation according to CSN 060320 can be determined from the equation:

$$
Q_{\mathrm{DHW}, \mathrm{d}}=Q_{2 \mathrm{t}}+Q_{2 \mathrm{z}}
$$

Where the theoretical withdrawn heat from the heater, $\mathrm{Q}_{2}$, in $\mathrm{kWh}$, is determined by the relationship (2) and the heat lost during heating and distribution, $\mathrm{Q}_{2 z}$ in $\mathrm{kWh}$, can be determined by the relationship (3):

$$
Q_{2 \mathrm{t}}=c \cdot V_{2 \mathrm{P}}\left(\theta_{2}-\theta_{1}\right)
$$

$$
Q_{2 \mathrm{z}}=Q_{2 \mathrm{t}} \cdot \mathrm{z}
$$

Where $V_{2 \mathrm{P}}$ is DHW requirement in the period $\left[\mathrm{m}^{3}\right]$

$\left.\mathrm{m}^{3} \mathrm{~K}\right]$

c specific heat capacity [kWh/

$z \quad$ energy loss coefficient [-]

$\theta_{1} \quad$ inlet water temperature $\left[{ }^{\circ} \mathrm{C}\right]$

$\theta_{2} \quad$ outlet water temperature $\left[{ }^{\circ} \mathrm{C}\right]$

The annual energy demand for DHW generation in accordance with standards is obtained by calculating the equations above, and multiplying with the number of days of operation:

$$
Q_{D H W}=365 \cdot(1+z) \frac{\rho c \cdot V_{2 \mathrm{P}}\left(\theta_{2}-\theta_{1}\right)}{3600}
$$

Where $\rho$ is density of water $\left[\mathrm{kg} \cdot \mathrm{m}^{-3}\right]$.

According to standards, the amount of water per person per day is up to 82 litres and energy loss coefficient is up to $50 \%$. This is significant overdimensioning of the solar DHW system. According to these requirements, the energy required for DHW generation per year would be. 


$$
\begin{gathered}
Q_{D H W}=365 \cdot(1+0,5) \frac{1000 \cdot 4186 \cdot 0,328(55-10)}{3600} \\
Q_{D H W}=9,4 \mathrm{MWh} \cdot \mathrm{yr}^{-1}
\end{gathered}
$$

According to experts, the value of the amount of water is too high. It can actually range from 25 to 50 litre per person per day, which also correspond to more realistic values in the standard ČSN EN 15361-3. Similarly, energy losses are up to $50 \%$ according to the standard. In real terms, thermal energy losses in DHW distribution and generation are from 20 to $40 \%$. For the building under consideration, the water consumption is set at 45 litres per person per day and the energy loss coefficient is 0.25 . According to these new requirements, the energy required for DHW generation per year is:

$$
\begin{gathered}
Q_{D H W}=365 \cdot(1+0,25) \frac{1000 \cdot 4186 \cdot 0,18(55-10)}{3600} \\
Q_{D H W}=4,3 \mathrm{MWh} / \text { year }
\end{gathered}
$$

The difference of energy is more than $50 \%$ for these examples. This is also reflected in the design of the energy source, eg. the number of solar collectors, the size of DHW tank, parameters of auxiliary heater, etc. All these values are the input parameters for determining the economic returns of selected systems and energy sources. Important point is that different energy sources (natural gas or electricity) have different prices per unit of energy.

\subsection{Solar domestic hot water system}

As already mentioned, the selection of optimal parameters of the solar DHW system is the important part of its design. An example in this article is the assessment of the solar thermal system for DHW generation. To determine the basic parameters is used simplified calculation according to TNI 73 0302. These calculations contain a number of simplifications for easy application for solar systems designing with feedback on operating parameters. On the other hand, there are some disadvantages: the predetermined climatic data, so it is problematic to compare the results of the calculation with the measurement on the real system; the constant temperature in the collectors over the year and calculation the thermal losses by a flat rate from the thermal gains. All this leads to optimistic results, especially in the winter months, when the system can hardly be used, but the calculations achieve comparatively high profits.

The biggest advantage of this standard is to determine the actual profits of the solar system, $\mathrm{Q}_{\mathrm{ss}, \mathrm{u}}$, based on the comparison of the theoretically usable heat gains of the solar collectors, $\mathrm{Q}_{\mathrm{k}, \mathrm{u}}$, and the total heat demand, $\mathrm{Q}_{\mathrm{p}, \mathrm{c}}$, to be covered. The specific heat gain from the collectors, $q_{\mathrm{k}}$ in $\mathrm{kWh} \cdot \mathrm{m}^{-2}$ day $^{-1}$, can be obtained using the equation:

$$
q_{\mathrm{k}}=\eta_{\mathrm{k}} \cdot H_{\mathrm{T}, \mathrm{day}}
$$

Where $\quad H_{\mathrm{T}, \text { day }}$ is daily solar irradiation $\left[\mathrm{kWh} \cdot \mathrm{m}^{-2} \mathrm{~d}^{-1}\right]$

Average daily efficiency is calculated using the equation:

$$
\eta_{\mathrm{k}}=\eta_{\mathrm{o}}-a_{1}\left(\frac{\theta_{\mathrm{m}}-\theta_{\mathrm{es}}}{G_{\mathrm{T}, \mathrm{m}}}\right)-a_{2} \frac{\left(\theta_{\mathrm{m}}-\theta_{\mathrm{es}}\right)^{2}}{G_{\mathrm{T}, \mathrm{m}}}
$$

Where $\eta_{\mathrm{o}}$ is intercept efficiency [-]

$$
\begin{array}{ll}
a_{1} & \text { efficiency slope }\left[\mathrm{Wm}^{-2} \mathrm{~K}^{-1}\right] \\
a_{2} & \text { efficiency curvature }\left[\mathrm{Wm}^{-2} \mathrm{~K}^{-2}\right] \\
\theta_{\mathrm{m}} & \text { mean temp. of the heat }
\end{array}
$$

transfer fluid $\left[{ }^{\circ} \mathrm{C}\right]$

$$
\theta_{\mathrm{e}} \text { ambient temp. around the }
$$
collector $\left[{ }^{\circ} \mathrm{C}\right]$

$$
\theta_{\mathrm{es}} \quad \text { average temp. during sunshine }
$$

$$
\begin{array}{ll}
G & \text { incident radiation }\left[\mathrm{Wm}^{-2}\right] \\
G_{\mathrm{T}, \mathrm{m}} & \text { mean incident radiation }
\end{array}
$$

$\left[\mathrm{Wm}^{-2}\right] .[7]$

The area of solar collectors, $A_{\mathrm{c}}$ in $\mathrm{m}^{2}$, is:

$$
A_{\mathrm{c}}=\frac{Q_{\mathrm{pc}}}{q_{\mathrm{c}}}=\frac{(1+p) \cdot Q_{\mathrm{p}}}{\eta_{c} \cdot H_{\mathrm{T}, \mathrm{day}}}
$$

Where $Q_{\mathrm{p}}$ is daily heat demand [kWh/day]

[kWh/day]

$$
Q_{\mathrm{pc}} \text { total daily heat demand }
$$

$p \quad$ energy loss coefficient [-]. [7]

The equations above were related to the daily energy balance. The theoretically exploitable gains of the solar system in each month are defined as:

$$
\begin{array}{r}
Q_{k, u}=0,9\left[\eta_{\mathrm{o}}-a_{1}\left(\frac{\theta_{\mathrm{m}}-\theta_{\mathrm{es}}}{G_{\mathrm{T}, \mathrm{m}}}\right)-\right. \\
\left.-a_{2} \frac{\left(\theta_{\mathrm{m}}-\theta_{\mathrm{es}}\right)^{2}}{G_{\mathrm{T}, \mathrm{m}}}\right] H_{T, \text { day }} n \cdot A_{c}(1-p)
\end{array}
$$

Where $n$ is days in each month. [6]

\subsection{Economics}

The research also explores the economic return of the proposed systems. Monitored parameters include payback period, discounted payback period, net present value and internal rate of return. These terms are explained and described in the following text.

\subsubsection{Payback period}

Payback period is a very often used economic criterion. It is simple, but not so accurate. It does not consider inflation, discount or lifetime of the project. However, it can be used as a simple indicator of return on investment. Payback period is calculated as: 


$$
T_{S}=I N / C F
$$

Where $\quad I N$ is investments, costs of the project;

CF cash flow, average annual yield.

\subsubsection{Discounted payback period}

The discounted payback period (DPP) formula is used to calculate the length of time to recoup an investment based on the investment's discounted cash flows. By discounting each individual cash flow, the DPP formula takes into consideration the time value of money [8]:

$$
T_{d}=\frac{\ln \left(1+\frac{I N}{C F} \cdot(\alpha-r)\right)}{\ln \frac{(1+\alpha)}{(1+r)}}
$$

\section{Where $\quad \alpha$ is inflation (CNB forecast for 2017 is $2 \%$ ); \\ $r \quad$ discount (around $5 \%$ )}

\subsubsection{Net present value}

Net present value (NPV) is the difference between the present value of the future cash flows from an investment and the amount of investment. The present value of the expected cash flows is computed by discounting them at the required rate of return [9]:

$$
N P V=C F \frac{(1+r-\alpha)^{t}-1}{(r-\alpha)(1+r-\alpha)^{t}}-I N
$$

\section{Where $\quad t$ is project lifetime [year].}

Positive net present value means a better return and negative net present value means a worse return than the return from zero net present value. It is one of the discounted cash flow techniques used in the comparative of investment proposals where the flow of income varies over time. [9]

\subsubsection{Internal rate of return}

Internal rate of return (IRR) method also takes into account the time value of money. It analyses an investment project by comparing the internal rate of return to the minimum required rate of return. The internal rate of return is the rate at which an investment project promises to generate a return during its useful life. Internal rate of return is the discount rate at which a project's net present value becomes equal to zero [10].

$$
N P V=0 \Rightarrow I R R
$$

If the internal rate of return of the investment project is greater than or equal to the minimum required rate of return, the project is considered acceptable otherwise the project is rejected.

\section{Methods}

Methods of optimizing are based on calculations and simulations. On these data, it can find the best option of the solar system in technical point of view. After that, it can be done investment assessment of each technical solution of the solar water heating system. The aim is to find the best technical and economical option.

This chapter deals with the practical applications of the mentioned calculations. Part of the chapter is the use of computational methods according to standards and their comparison with the results obtained from dynamic simulations of the same configurations for real climatic conditions. For accurate analysis was made a model of the solar system in the TRNSYS simulation software, see Fig. 1. The simulations used the measured data from the meteorological station located at the FAI TBU in Zlin (Czech Republic). These data for climatic conditions were measured in 2017.

TRNSYS software was already used for research of solar water heating systems. On the other hand, these researches often use just inbuilt weather module for a Typical Meteorological Year [11,12]. In this article is used real data for better verification and more accurate results.

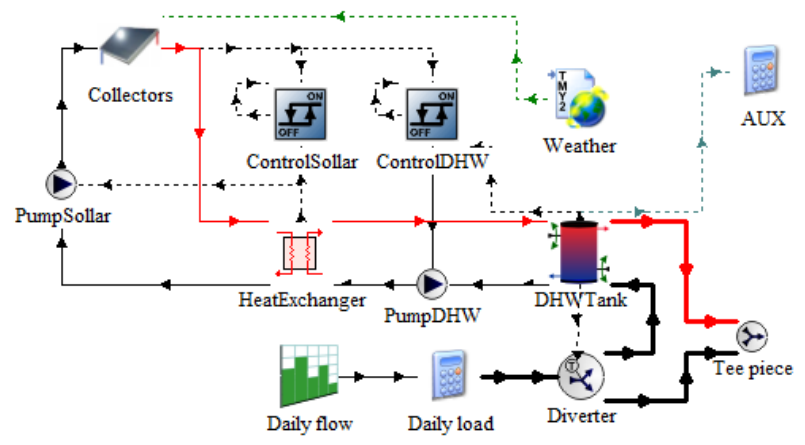

Fig. 1. Simulation model of the solar water heating system.

The proposed system contains thermal solar collectors, desk exchanger, two pumps, control elements, and a DHW storage tank. The solar system is in operation when the outside temperature is above $5{ }^{\circ} \mathrm{C}$. The water temperature in the solar collector circuit is compared to the water temperature at the bottom of the DHW tank. If it is lower in the bottom of the tank, the tank is warming up to the setpoint temperature, then the solar system is shut down. The system is designed to be able to be used even with lower solar radiation. This is achieved by circulating of liquid in the solar circuit. This circulation of liquid in the solar collectors leads to its heating to a higher temperature. When the liquid reached higher temperature, it is transferred to the heat exchanger in the DHW tank.

For calculations and dynamic simulations, the first step is to determine the input parameters for different configurations. The basic parameters of the solar system:
- Number of persons:
4 persons
- DHW consumption: 
- inlet water temperature: $10^{\circ} \mathrm{C}$

- outlet water temperature: $55^{\circ} \mathrm{C}$

- DHW tank volume: $\quad 0,2 \mathrm{~m}^{3}$

Parameters of solar collectors:

- number of collectors: 1 to 5 pcs

- area of the collector: $\quad 2,39 \mathrm{~m}^{2}$

- intercept efficiency $\eta_{\mathrm{o}}$ : 0,794

- efficiency slope $a_{1}$ : $\quad 3,639 \mathrm{Wm}^{-2} \mathrm{~K}^{-1}$

- efficiency curvature $a_{2}$ : $0,0168 \mathrm{Wm}^{-2} \mathrm{~K}^{-2}$

- collector slope: $\quad 45^{\circ}$

- azimuth: $\quad 0^{\circ} \mathrm{S}$

The results of the calculations of the equations 1 to 8 are shown in the following table. The results of the energy demands for the DHW generation for a fourmember family are based on TNI 73 0302. The calculations take into account the DHW consumption according to the input parameters: $Q_{\mathrm{p}, \mathrm{DHW}, 82}, Q_{\mathrm{p}, \mathrm{DHW}, 45}$, a $Q_{\mathrm{p}, \text { DHW }, 35}$, i.e. 82,45 and $351 \cdot \mathrm{p}^{-1}$ day $^{-1}$.

Better efficiency should get by using of solar tracker for enhancement of the thermal efficiency of solar water heating system [13]. In our case is used a common system with static solar collectors.

Tab. 1. Monthly solar gains and heat demand for DHW generation

\begin{tabular}{|c|c|c|c|c|c|}
\hline \multirow{2}{*}{ Month } & $\theta_{\mathrm{e}}$ & $\mathrm{H}_{\mathrm{DHW}, \mathrm{m}}$ & $\mathrm{Q}_{\mathrm{p}, \mathrm{DHW}, 35}$ & $\mathrm{Q}_{\mathrm{p}, \mathrm{DHW}, 45}$ & $\mathrm{Q}_{\mathrm{p}, \mathrm{DHW}, 82}$ \\
\hline & ${ }^{\circ} \mathrm{C}$ & $\mathrm{kWh} / \mathrm{m}^{2}$ & $\mathrm{kWh}$ & $\mathrm{kWh}$ & $\mathrm{kWh}$ \\
\hline JAN & $-1,5$ & 34,1 & 261 & 336 & 612 \\
\hline FEB & 0,0 & 55,2 & 236 & 303 & 553 \\
\hline MAR & 3,2 & 99,2 & 261 & 336 & 612 \\
\hline APR & 8,8 & 118,8 & 253 & 325 & 592 \\
\hline MAY & 13,6 & 150,0 & 261 & 336 & 612 \\
\hline JUN & 17,3 & 158,7 & 253 & 325 & 592 \\
\hline JUL & 19,2 & 160,9 & 261 & 336 & 612 \\
\hline AUG & 18,6 & 146,0 & 261 & 336 & 612 \\
\hline SEP & 14,9 & 118,5 & 253 & 325 & 592 \\
\hline OCT & 9,4 & 74,4 & 261 & 336 & 612 \\
\hline NOV & 3,2 & 36,3 & 253 & 325 & 592 \\
\hline DEC & $-0,2$ & 23,9 & 261 & 336 & 612 \\
\hline \multicolumn{2}{|c|}{ SUM } & 1176 & 3075 & 3955 & 7205 \\
\hline
\end{tabular}

The same procedure was performed using the TRNSYS software. The table below, see Tab. 2, represents the values of average monthly temperatures, monthly solar gains and real heat demand based on real data measured in 2017. As can be seen, the total solar radiation per year is very similar in both cases. However, the difference is in the distribution of the monthly solar radiation over the year. In theoretical calculation according to standards, the values are continuously increasing and decreasing over the year. These values were higher in the winter months and lower in the summer months in 2017, see Fig. 2.

Tab. 2. Monthly solar gains and heat demand for DHW generation - TRNSYS

\begin{tabular}{|c|c|c|c|c|c|}
\hline \multirow{2}{*}{ Month } & $\theta_{\mathrm{e}}$ & $\mathrm{H}_{\mathrm{DHW}, \mathrm{m}}$ & $\mathrm{Q}_{\mathrm{p}, \mathrm{DHW}, 35}$ & $\mathrm{Q}_{\mathrm{p}, \mathrm{DHW}, 45}$ & $\mathrm{Q}_{\mathrm{p}, \mathrm{DHW}, 82}$ \\
\cline { 2 - 6 } & ${ }^{\circ} \mathrm{C}$ & $\mathrm{kWh} / \mathrm{m}^{2}$ & $\mathrm{kWh}$ & $\mathrm{kWh}$ & $\mathrm{kWh}$ \\
\hline JAN & $-5,5$ & 59,3 & 227 & 293 & 536 \\
\hline FEB & 1,5 & 59,4 & 203 & 265 & 485 \\
\hline MAR & 7,5 & 114,7 & 222 & 288 & 536 \\
\hline APR & 8,5 & 110,9 & 213 & 280 & 519 \\
\hline MAY & 15,2 & 132,0 & 220 & 289 & 537 \\
\hline JUN & 20,4 & 132,2 & 211 & 281 & 519 \\
\hline JUL & 21,3 & 123,2 & 225 & 291 & 537 \\
\hline AUG & 13,9 & 140,2 & 211 & 286 & 537 \\
\hline SEP & 10,3 & 97,6 & 213 & 281 & 519 \\
\hline OCT & 4,8 & 83,4 & 223 & 292 & 537 \\
\hline NOV & 1,5 & 44,4 & 220 & 285 & 519 \\
\hline DEC & 10,0 & 27,9 & 229 & 294 & 537 \\
\hline \multicolumn{2}{|c|}{ SUM } & $\mathbf{1 1 2 5}$ & $\mathbf{2 6 1 7}$ & $\mathbf{3 4 2 5}$ & $\mathbf{6 3 1 8}$ \\
\hline
\end{tabular}

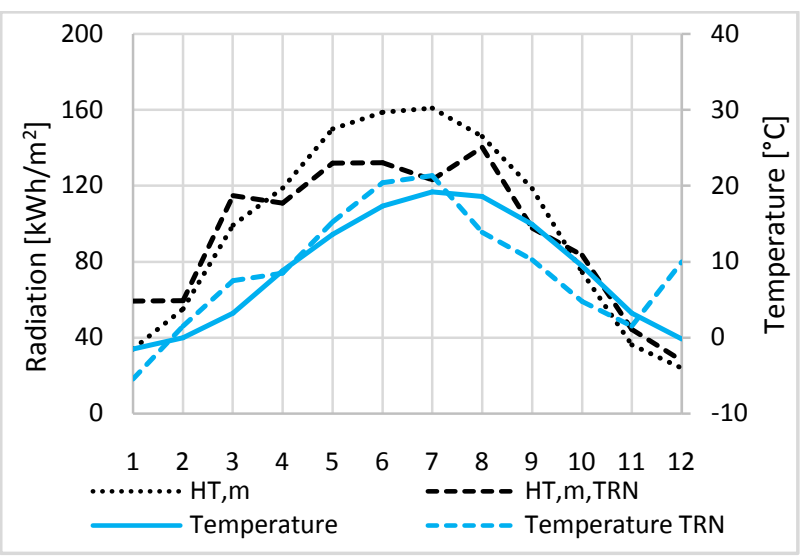

Fig. 2. Average monthly solar gains and temperature.

\section{Results and discussion}

Based on the data obtained so far, it is possible to start solving the optimization of the proposed solar water heating system. The optimization is based on the search for the optimal number of solar collectors for the different DHW consumption. The default number of solar collectors is based on the calculation according to standards - for the lowest consumption, the recommended number of solar collectors is 1 or 2 pieces; for the medium consumption, it is 2 or 3 pcs; and for the highest consumption, it is 4 or 5 pcs. From a technical point of view, the optimal system can cover as much heat demand as possible and it can use the maximum installed capacity at the same time. From an economic point of view, this situation is also appropriate, as there is a positive ratio of investment and energy savings. The following text deals with a technical assessment first and then with an economic one.

The following tables (Tab. 3, Tab. 4 and Tab. 5) show the results of the calculations for a different number of solar collectors and different DHW consumption. It is possible to see the total heat demand to be covered, $\mathrm{Q}_{\mathrm{p}, \mathrm{DHW}}$, the theoretically usable heat gains of the solar collectors, $\mathrm{Q}_{\mathrm{k}, \mathrm{u}}$, and the real utilization of the solar system, $\mathrm{Q}_{\mathrm{ss}, \mathrm{u}}$. The table also contains the percentage 
utilization of solar radiation, $\mathrm{n}_{\text {sol }}$, and installed power of solar collectors, $\mathrm{n}_{\mathrm{sc}}$. The percentage utilization of installed power is the ration of the heat real used and the theoretically achievable maximum.

Tab. 3. Thermal gains and system utilization, 1 or 2 pcs

\begin{tabular}{|c|c|c|c|c|c|c|c|}
\hline Pieces & pcs & \multicolumn{3}{|c|}{1} & \multicolumn{3}{|c|}{2} \\
\hline Cons. & $1 \cdot \mathrm{p}^{-1}$ day $^{-1}$ & 35 & 45 & 82 & 35 & 45 & 82 \\
\hline$Q_{p, D H W}$ & $\mathrm{kWh} /$ year & 3075 & 3955 & 7205 & 3075 & 3955 & 7205 \\
\hline$Q_{k, u}$ & $\mathrm{kWh} /$ year & 1210 & 1210 & 1210 & 2420 & 2420 & 2420 \\
\hline$Q_{s s, u}$ & $\mathrm{kWh} /$ year & 1210 & 1210 & 1210 & 2085 & 2363 & 2420 \\
\hline $\mathrm{n}_{\text {sol }}$ & $\%$ & 39 & 31 & 17 & 68 & 60 & 34 \\
\hline $\mathrm{n}_{\mathrm{sc}}$ & $\%$ & 100 & 100 & 100 & 86 & 98 & 100 \\
\hline
\end{tabular}

Tab. 4. Thermal gains and system utilization, 3 or 4 pcs

\begin{tabular}{|c|c|c|c|c|c|c|c|}
\hline Pieces & pcs & \multicolumn{3}{|c|}{3} & \multicolumn{3}{|c|}{4} \\
\hline Cons. & $1 \cdot \mathrm{p}^{-1}$ day $^{-1}$ & 35 & 45 & 82 & 35 & 45 & 82 \\
\hline$Q_{p, \text { DHW }}$ & $\mathrm{kWh} /$ year & 3075 & 3955 & 7205 & 3075 & 3955 & 7205 \\
\hline$Q_{k, u}$ & $\mathrm{kWh} /$ year & 3630 & 3630 & 3630 & 4840 & 4840 & 4840 \\
\hline$Q_{s s, u}$ & $\mathrm{kWh} /$ year & 2370 & 2823 & 3630 & 2524 & 3075 & 4536 \\
\hline $\mathrm{n}_{\mathrm{sol}}$ & $\%$ & 77 & 71 & 50 & 82 & 78 & 63 \\
\hline $\mathrm{n}_{\mathrm{sc}}$ & $\%$ & 65 & 78 & 100 & 52 & 64 & 94 \\
\hline
\end{tabular}

The values from the tables above are graphically represented in the graph below, see Fig. 3. The heat demand for DHW generation and maximum solar gains of a different number of solar collectors are clearly visible in this figure. If the solar gains exceed the heat demand, the percentage utilization of the installed capacity is reduced.

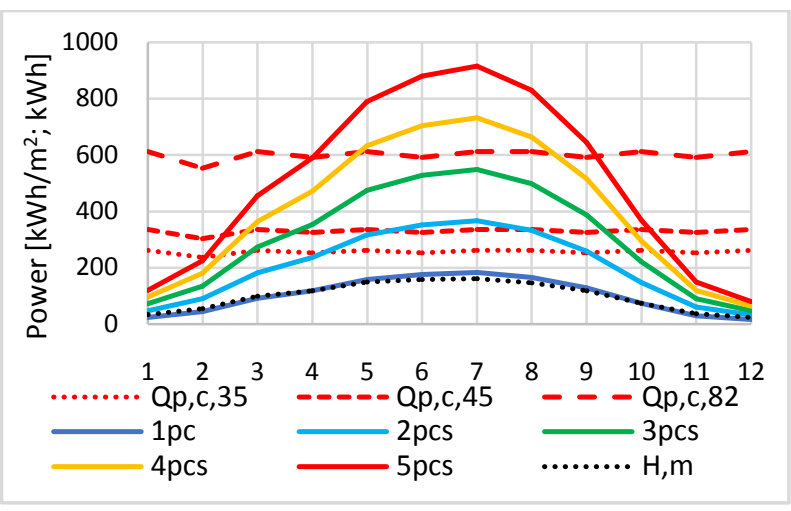

Fig. 3. Heat demands and maximum solar gains over the year.

As mentioned earlier, the optimal system can cover as much heat demand as possible and it can use the maximum installed capacity at the same time. It means the system works with the minimum of energy surplus. From the tables, Tab. 3 and Tab. 4, and the graph above, Fig. 3, it is clear that one piece of collector covers from 17 to $39 \%$ of the heat demand and its power is utilized at $100 \%$. This shows that the system is underdimensioned and unable to cover the heat demand in any period. For two and three pieces, the situation is more positive. The coverage of the heat demand is from 34 to $77 \%$ and the power utilization is 65 to $100 \%$. For more collectors, the coverage of the heat demand is further increased, but the percentage utilization of the installed power decreases, see Tab. 4. It means the system is overdimensioned. The system with two or three solar collectors appears to be optimal for the designed conditions.

The following tables, Tab. 5 and Tab. 6, and the graph, Fig. 4, represent the same case as above, but the results are obtained by dynamic simulations.

Tab. 5. Thermal gains and system utilization, 1 or 2 pcs, TRN

\begin{tabular}{|c|c|c|c|c|c|c|c|}
\hline Pieces & pcs & \multicolumn{3}{|c|}{1} & \multicolumn{3}{|c|}{2} \\
\hline Cons. & $1 \cdot \mathrm{p}^{-1}$ day $^{-1}$ & 35 & 45 & 82 & 35 & 45 & 82 \\
\hline$Q_{p, \text { DHW }}$ & $\mathrm{kWh} /$ year & 2617 & 3425 & 6318 & 2617 & 3425 & 6318 \\
\hline$Q_{k, u}$ & $\mathrm{kWh} /$ year & 1374 & 1409 & 1487 & 2714 & 2807 & 3006 \\
\hline$Q_{s s, u}$ & $\mathrm{kWh} /$ year & 1374 & 1409 & 1487 & 2186 & 2650 & 3006 \\
\hline $\mathrm{n}_{\text {sol }}$ & $\%$ & 53 & 41 & 24 & 84 & 77 & 48 \\
\hline $\mathrm{n}_{\mathrm{sc}}$ & $\%$ & 100 & 100 & 100 & 81 & 94 & 100 \\
\hline
\end{tabular}

Tab. 6. Thermal gains and system utilization, 3 or 4 pcs, TRN

\begin{tabular}{|c|c|c|c|c|c|c|c|}
\hline Pieces & pcs & \multicolumn{3}{|c|}{3} & \multicolumn{3}{|c|}{4} \\
\hline Cons. & $1^{-1} \cdot \mathrm{p}^{-1}$ day $^{-1}$ & 35 & 45 & 82 & 35 & 45 & 82 \\
\hline$Q_{p, D H W}$ & $\mathrm{kWh} /$ year & 2617 & 3425 & 6318 & 2617 & 3425 & 6318 \\
\hline$Q_{k, u}$ & $\mathrm{kWh} /$ year & 3742 & 3905 & 4305 & 4660 & 4852 & 4852 \\
\hline$Q_{s s, u}$ & $\mathrm{kWh} /$ year & 2415 & 2988 & 4298 & 2501 & 3177 & 4782 \\
\hline $\mathrm{n}_{\mathrm{sol}}$ & $\%$ & 92 & 87 & 68 & 96 & 93 & 76 \\
\hline $\mathrm{n}_{\mathrm{sc}}$ & $\%$ & 65 & 77 & 100 & 54 & 65 & 99 \\
\hline
\end{tabular}

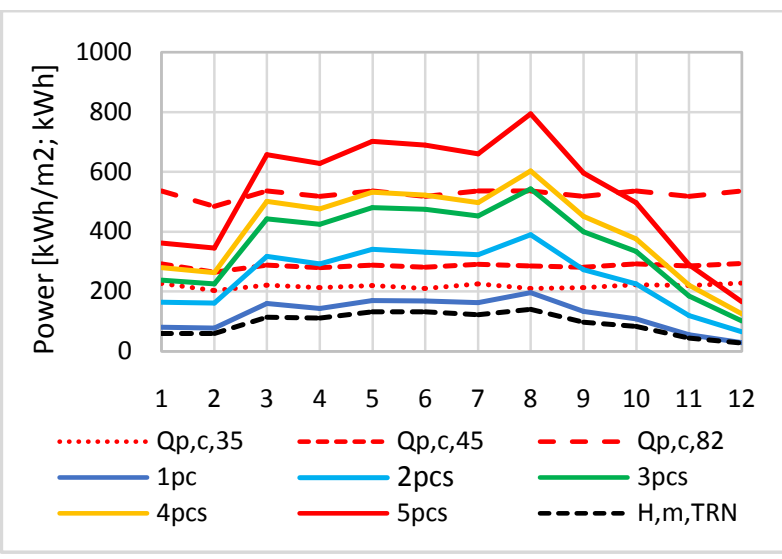

Fig. 4. Heat demands and maximum solar gains, TRNSYS.

The simulation results are more positive than the calculation results. However, one solar collector is still not capable to cover too much heat demand. In the extreme case, this option is useful for the lowest DHW consumption where the energy coverage is up to $53 \%$. The options with 2 or 3 pieces are the most suitable. The energy coverage is between 48 and $92 \%$ and the installed capacity utilization is between 65 and $100 \%$. For more pieces the results of the energy coverage are similar, but the capacity utilization is decreased, so the system is over-dimensioned, see Tab. 6.

As can be seen, the difference between one and two pieces of solar collectors is considerable in both 
methods. However, adding more pieces does not provide adequate additional energy coverage. It only leads to increasing investments with decreasing usability. Among other things, over-dimensioning of the system leads to stagnation and thus to degradation of the heat transfer medium and solar collectors. [14-17]

The next charts show the results for higher DHW consumption - 45 1.p-1day-1, see Fig. 5 and Fig. 6. This option can cover almost any situation in a normal household, so it is chosen as the default. In the charts, it can be seen that 2 pieces of solar collectors almost ideally cover the heat demand in the months of April to September, see Fig. 6. This option has optimal use of installed power with only small surpluses. This fact will also be reflected in the economic assessment of the investment.

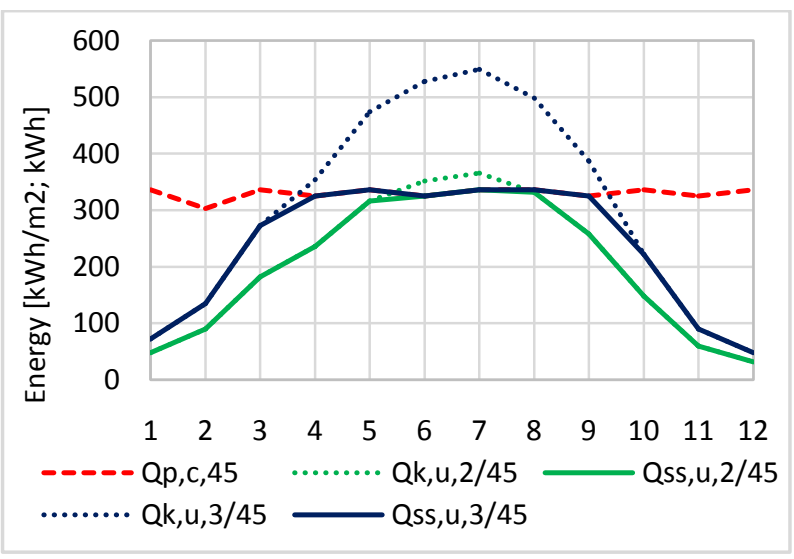

Fig. 5. Two and three pieces, consumption $451 \cdot \mathrm{p}^{-1} \mathrm{day}^{-1}$.

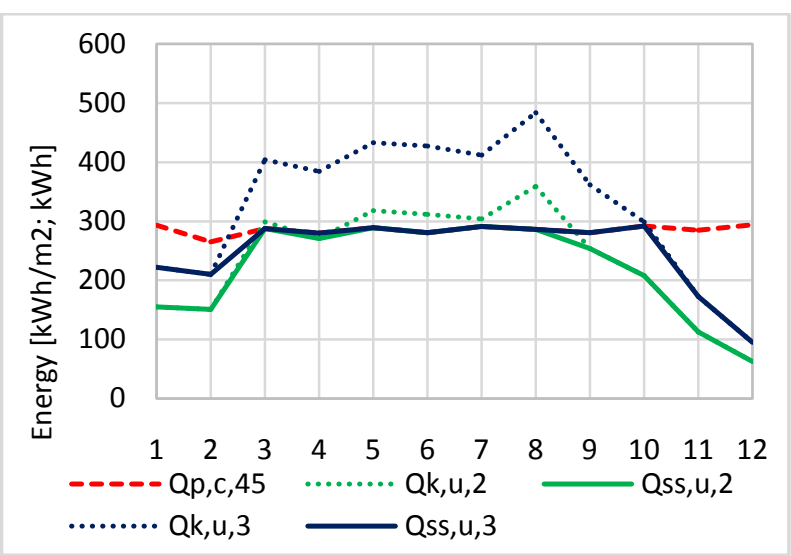

Fig. 6. Two and three pieces, consumption $451 \cdot \mathrm{p}^{-1} \mathrm{day}^{-1}$, TRN.

From the obtained data and information, it is possible to move on to the economic evaluation of investments of individual variants of the solar DHW system.

\section{Investment assessment}

This chapter uses prices in Czech Republic and data get by CNB's website (Czech National Bank) [18]: exchange rate $1 \mathrm{EUR}=25.5 \mathrm{CZK}$, inflation $2 \%$ and discount rate $0.5 \%$. When assessing investments, simplified prices for individual investments were considered from the point of view of technology, ie the solar system consists of solar collector (about 430 EUR), DHW tank (550 to 710 EUR) and equipment (about 200 EUR). The energy prices are also important: electricity about 45.5 EUR/MWh at a low tariff (D25d, D26d) and gas - about 35.7 EUR/MWh in 2018.

Demonstration of the results of each solution can be seen in the charts below, Fig. 7, Fig. 8 and Fig. 9, which include Discounted Payback Period, Net Present Value, and Internal Rate of Return.

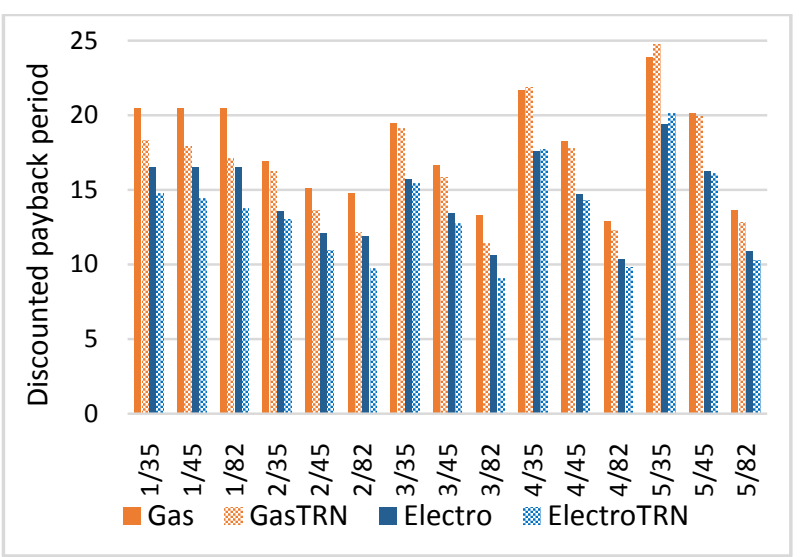

Fig. 7. Discounted payback period.

From the charts, see Fig. 7, it can be seen that the discounted payback period is always lower in the case of DHW generation by electricity than by natural gas. There are also differences in calculations and simulations. Simulation results with real climate conditions are slightly better in 2017 . It is possible to conclude that system with two solar collectors has the lowest payback period for low and medium consumption of DHW. The three-piece or four-piece system is the best option for the highest DHW consumption.

Similar research of payback period was made for Greece [19]. The solar water heater system located in Northern Greece consists of a flat plate collector panel 4 $\mathrm{m} 2$ and a 200-litre hot water tank. In this research payback period was just about 5 year. This is caused by sunny climate and by lower prices of components.

Another concept in the investment assessment is the net present value of the project (NPV). The charts, see Fig. 8, shows the values of each variant.

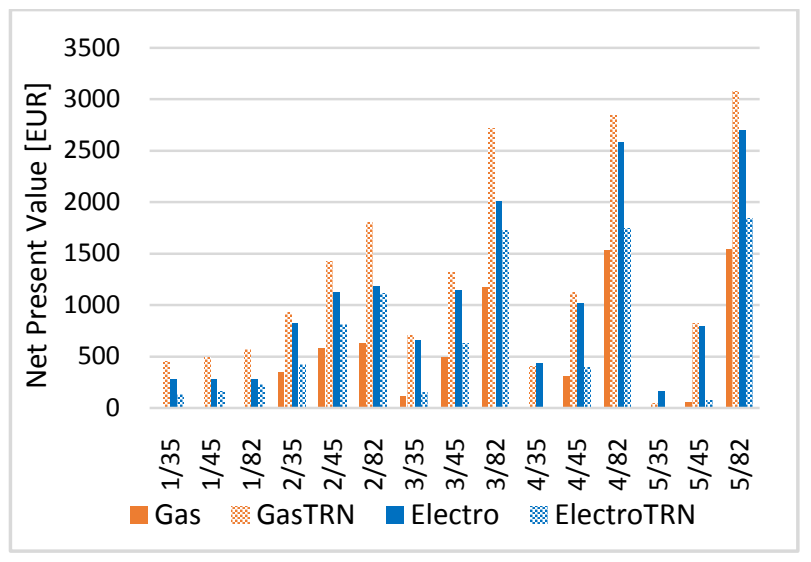

Fig. 8. Net present value.

The two-piece system is again the best option for low and medium DHW consumption. The one-piece 
system has very low or even negative values of NPV. The systems with more pieces of collectors have good values of NPV, but just for the highest DHW consumption, so these are not profitable for standard lower consumption.

The last charts, Fig. 9, shows values of the Internal Rate of Return (IRR). This value indicates the relative profitability of the project over its lifetime. When the IRR is higher than the discount rate, investment is acceptable. The higher IRR means the higher investment return. As it can be seen, the one-piece system has very low IRR values for all options. The two-piece system has very positive values of IRR in every case. Three-piece system is slightly worse than previous, but it is still acceptable for higher DHW consumption. Four and fivepiece systems are profitable just for very high DHW consumption.

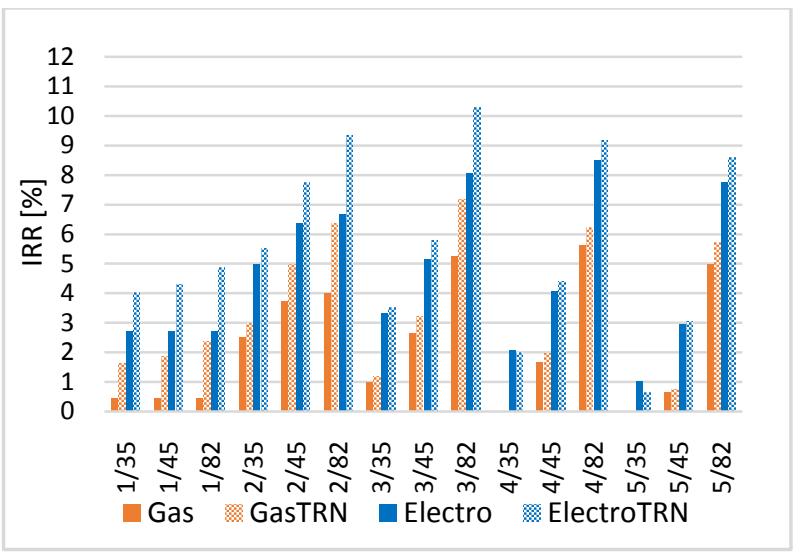

Fig. 9. Internal Rate of Return.

The result of the investment assessment is that the best possible option is the solar water heating system with two solar collectors. This option has the optimal values of discounted payback period, net present value and internal rate of return. These values are optimal at the same time and at the all values of DHW consumption.

\section{Conclusion}

The article dealt with the economic evaluation of investment and optimization of the solar water heating system for family houses. Part of the article was the design and calculation of it according to standards, and then its dynamic simulations were done. From these calculations and simulations, the values of discounted payback period, net present values and internal rate of returns were obtained. The result of the article is that the solar water heating system with two solar collectors is the best option for the four-person family household. This option is universal for all conditions of hot water consumption per person per day. The research produced a comparison of the results of the calculations and simulations, from which the optimal parameters were determined. These recommendations lead to significant savings in energy, money and investments. The chosen system will ensure the economic and energy efficient operation of the renewable energy source.
This work was supported by the Ministry of Education, Youth and Sports of the Czech Republic within the National Sustainability Programme project No. LO1303 (MSMT7778/2014) and also by the European Regional Development Fund under the project CEBIA-Tech No. CZ.1.05/2.1.00/03.0089 and also by the Internal Grant Agency of Tomas Bata University under the project No. IGA/CebiaTech/2018/001

\section{References}

1. C.J. Koroneos, E.A. Nanaki. J Clean Prod. 37, 154161 (2012)

2. ČSN 06 0320. Praha: UNMZ - Czech Office For Standards, Metrology and Testing (2006)

3. EN 12828:2012+A1:2014. Brussel: CEN (2014)

4. EN 12831-3:2018. Brussel: CEN (2018)

5. EN 15316-3:2017. Brussel: CEN (2017)

6. TNI 73 0302. Praha: UNMZ - Czech Office For Standards, Metrology and Testing (2014)

7. Heating guide. Praha: CSTZ - Czech Association For Technical Equipment, (2007)

8. Finance Formulas: Discounted Payback Period (DPP), (2018)

9. Business Dictionary: Net present value (NPV). WebFinance, Austin (2018)

10. Accounting for management: Internal rate of return method, (2017)

11. R.L. Shrivastava, V. Kumar, S.P. Untawale. Renew Sust Energ Rev. 67, 126-143 (2017)

12. Y. G. Yohanis, O. S. Popel, S. E. Frid, Yu. G. Kolomiets. International Journal of Sustainable Energy, 31, 347-364 (2012)

13. M.A. Abdelghani-Idrissi, S. Khalfallaoui, D. Seguin, L. Vernieres-Hassimi, S. Leveneur. Renew Energ. 119, 79-94 (2018)

14. P. V. Quiles, F. J. Aguilar, S. Aledo. Enrg Proced. 48, 172-180 (2014)

15. X. Zhang, S. You, W. Xu, X. Zheng, T. He, Z. Huang, L. Zhang, Y. Deng. Enrg Proced. 30, 824828 (2012)

16. J.C.S. Fernandes, A. Nunes, M.J. Carvalho, T.C. Diamantino. Sol Energ Mat Sol C. 160, 149-163 (2017)

17. X.J. Wang, L.J. Jiang, M. Du, L. Hao, X.P. Liu, Q.H. Yu. Enrg Proced. 49, 1747-1755 (2014)

18. Czech National Bank. Praha: CNB (2018)

19. Z. Wang, W. Yang, F. Qiu, X. Zhang, X. Zhao. Renew Sust Energ Rev. 41, 68-84 (2015) 